\title{
Adsorption of Benzene Butyl Phthalate with Mullti-walled Carbon Nanotubes/Ag nanoparticles and its Applications
}

\author{
SHADIYEH FALAHRODBARI \\ Department of Chemistry, Science and Research Branch, Islamic Azad University, \\ Tehran P.O.Box14515-755, Tehran,Iran. \\ *Corresponding author E-mail: Fshadif@Yahoo.Com \\ http://dx.doi.org/10.13005/ojc/330241
}

(Received: March 11, 2017; Accepted: March 04, 2017)

\begin{abstract}
In this experimental study was concentrated on the synchronic Removal of Benzyl Butyl Phthalate (BBP)from aqueous solutions by ultrasound-assisted adsorption onto multi walled carbon nanotubes/Ag nano particles composite (MWCNTs/Ag). multi walled carbon nanotubes was synthesized by chemical vapor deposition method then functionalized by carboxyl groups and finally characterized using XRD,SEM, EDX, FT-IR and BET method. The effects of variables such as $\mathrm{pH}$, sonication time, adsorbent dosage, and temperature on concurrent removal of BBP were studied and optimized. The kinetic and isotherm numerical observations could be well explained with the pseudosecond order kinetic model and the Langmuir isotherm model. The maximum adsorption valency of MWCNTs/Ag for Benzyl Butyl Phthalate (BBP) was $87.72 \mathrm{mg} \mathrm{g}$ "1. Thermodynamic parameters of adsorption process $\left(\Delta \mathrm{G}^{\circ}, \Delta \mathrm{H}^{\circ}, \Delta \mathrm{S}^{\circ}\right)$ were also evaluated. The overall adsorption process was exothermic and spontaneous inherent. The results indicated that Benzyl Butyl Phthalate (BBP) adsorption onto MWCNTs/Ag composite might be a physical adsorption.
\end{abstract}

Keywords: Ultrasonic assisted removal, Benzyl Butyl Phthalate (BBP), multi walled carbon nanotubes/Ag nanoparticles composite(MWCNTs/Ag), Isotherm, Kinetic, Thermodynamic.

\section{INTRODUCTION}

Phthalate acid ester (PAEs), generally known as phthalates, is used in many usable and household products, such as industrial plastics, polyvinyl chloride (PVC) products and personal care products. PAEs with high molecular weight such as bis (2-ethylhexyl) phthalate (DEHP) are used firstly as plasticizers to soften PVC products; while PAEs with low molecular weight such as diethyl phthalate (DEP), dibutyl phthalate (DBP), butyl benzyl phthalate (BBP) are widely used as solvents to hold color and scent in different usable and personal care product ${ }^{1,2}$. So, because of the broad use and 
possible migration, PAEs can be released from these PAEs-containing products. lately the widespread presence of PAEs has attracted considerable public attention because of the carcinogenic characteristics. The US Environmental Protection Agency (EPA) and several other agencies classified the PAEs as priority pollutants ${ }^{3,4}$.

phthalate esters also represent a major group of organic contaminants in the ultrapure water (UPW) used for fabrication of micro-device ${ }^{5}$. $n$-Butyl benzyl phthalate (BBP) is one of the most repeatedly identified phthalates in diverse environmental samples including groundwater, river water, drinking water, ocean water, soil, lake sediment and marine sediments. BBP exerted estrogenic activities in various tests ${ }^{6-8}$. BBP can be biologically degraded ${ }^{9,10}$.

lately, magnetic materials are being used because of their fast separation efficiency for investigating decomposition or deformation in chemical processes such as separation, purification 11-13.

Among them, the wide application of adsorption is emerged from advantages including simplicity, low cost, high efficiency, wide adaptability and availability of different adsorbents ${ }^{14}$.

Ultrasound irradiation is famous to accelerate chemical process due to the phenomenon of acoustic cavitation. Lately ultrasonic assisted adsorption process has been developed to favor the kinetic of the mass-transfer process of the adsorbate to the adsorbent and to reduce the time required for adsorption ${ }^{15}$.

The nature and characteristics of the adsorbent are of prime importance in this method. In practice, the major requirements for a solid sorbent are: (a) the fast and quantitative adsorption and elution, (b) a high surface area and high valency, and (c) high dispersibility in liquid samples ${ }^{16}$.

Carbon nanotubes (CNTs) are allotropes of carbon with a cylindrical nanostructure. Nanotubes have been constructed with length-to-diameter ratio of up to $132,000,000: 1^{17}$, significantly larger than for any other material. These cylindrical carbon molecules have infrequentcharacteristics, which are valuable for nanotechnology, electronics, optics and other fields of materials science and technology. In particular, owing to their extraordinary thermal conductivity and mechanical and electrical characteristics, carbon nanotubes may find applications as additives to various structural materials. Multiwalled carbon nanotubes (MWCNTs) can adsorb many atoms and molecules on their surface such as adsorption of metallic elements. Adsorption characteristic of MWCNTs is breather for adsorption of gases such as hydrogen and other gases. All of the compounds on the surface of MWCNTs adsorbed two major covalent bonds and non-covalent bonds ${ }^{18,19}$.

The structure and morphology of CNTs enable them to serve as a specific template for preparing metal nanoparticle-CNT nanohybrids ${ }^{20,21}$. The combination of these two materials (i.e. CNTs and nanoparticles) is particularly useful to integrate the characteristics of the two elements in hybrid materials for use in catalysis, energy storage and nanotechnology 20 .Many studies investigated the fabricating metal nanoparticle decorated CNTs and also measured their unique electrical, magnetic and optical characteristics ${ }^{22,23}$.

Among them, Ag nanoparticles (Ag-NPs) attached onto CNTs (Ag/CNTs) attracted significant attention due to their potential applications as catalysts ${ }^{24}$, optical limiters ${ }^{25}$ and advanced materials ${ }^{26}$. Electrons can engage in charge transfer with an asorbate molecule, particularly the one that also contains $\delta$ electrons. These unique characteristics make CNTs adsorb molecules with aromatic rings much stronger than other types of adsorbents.

A simple approach is proposed in the present study to decorate MW CNTs with Ag and obtain MWCNTs/Ag nanocomposite with better characteristics, especially, further adsorption quality compared to MWCNTs.

This report studied the adsorption characteristics of commercially-available multi-walled carbon nanoparticles (MWCNTs/Ag) composite for ultrasonic assisted removal of Benzyl Butyl Phthalate (BBP) from aqueous samples. All major factors affecting the batch adsorption process were investigated and optimized. Meanwhile, behaviors 
and mechanisms of heavy metal ions adsorption are comprehensively explored by kinetic and isotherm models as well as thermodynamic parameters.

\section{Experimental procedure}

\section{Apparatus and Characterization Methods}

The size and morphology of the magnetic composites were characterized by scan electron microscopy (SEM) using a field emission scanning electron microscope (FESEM, FEI Nova Nano SEM-600, Netherlands). The structure phases and average size of the synthesized adsorbents was analyzed by X-ray diffraction (XRD) (Shimadzu XRD Model 6000). Infrared absorption spectroscopy (IR) spectra were measured at room temperature on a Fourier transform infrared (FTIR) spectroscopy using the $\mathrm{KBr}$ Pellet technique ${ }^{27}$.

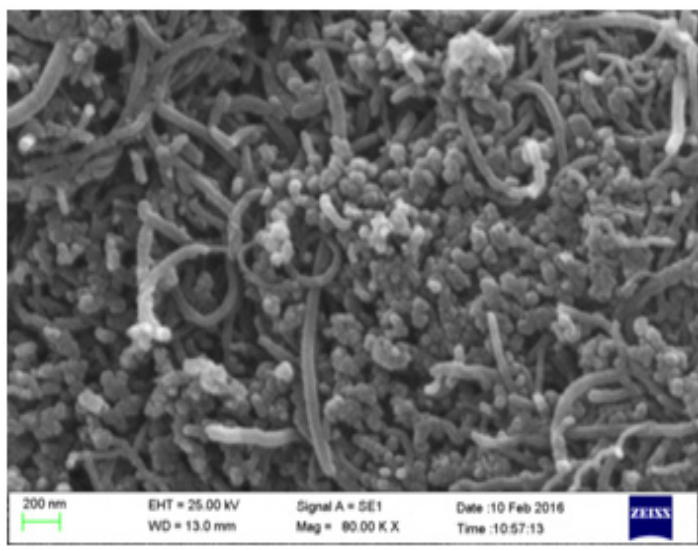

Fig. 1: SEM image of the prepared AgMWCNTs.

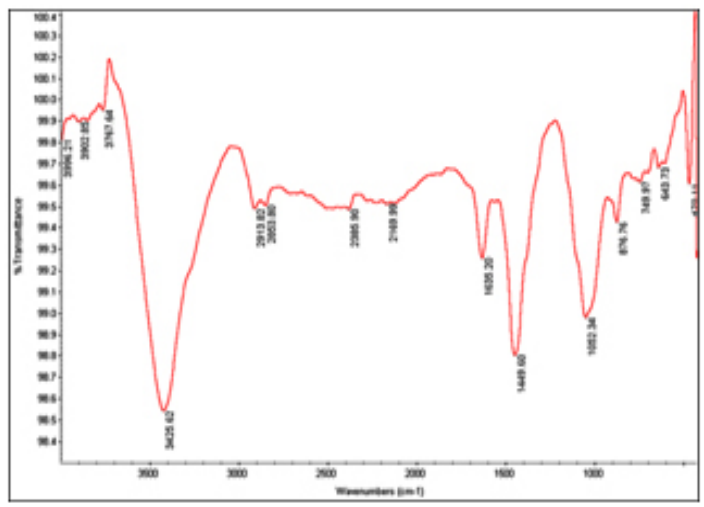

Fig. 2: FT-IR transmittance spectrum of the prepared Ag-MWCNTs.

\section{Materials}

Benzyl butyl phthalate, Silver nitrate, Ascorbic acid, multi-walled carbon nanotube sodium hydroxide and hydrochloric acid supplied from Merck (Darmstadt, Germany). Stock solutions were prepared by dissolving exact amount of nitrate salts of Benzyl butyl phthalate (BBP) in deionized water to the concentration of $1000 \mathrm{mg} \mathrm{L}^{-1}$. The standard and experimental solutions were obtained by diluting the stock solutions with deionized water. Deionized water (DI-water) obtained from a Millipore Continental Water System (Bedford, MA, USA) was used throughout this study.

\section{Preparation of multi walled carbon nanotubes/ Ag nanoparticles composite}

$2.5 \mathrm{~g}$ of MWCNTs was dispersed in $20 \mathrm{~mL}$ of distilled water through ultra-sonication for $30 \mathrm{~min}$. $0.5 \mathrm{~g}$ of $\mathrm{AgNO}_{3}$ was added into the solution with constant stirring at room temperature using the magnetic stirring for approximately $1 \mathrm{~h}$ to generate $\mathrm{Ag}^{+}$ions. $\mathrm{Ag}^{+}$ions grafted onto carbon nanotubes were reduced by adding ascorbic acid $(0.1 \mathrm{M})$ to the solution and $\mathrm{Ag}$ nanoparticles generated on the MWCNTs surface. After this process, the mix get filtered through a 0.45 membrane filter and dried under vacuum at $50 \mathrm{C}^{\circ}$ for 3 hours and then MWCNTs/Ag obtained.

\section{Batch adsorption experiments}

Batch adsorption experiments were carried out to determine the BBP adsorption isotherm onto MWCNTs/Ag composite and its thermodynamic characteristics:

BBP stock solution (50 mg L"1)was prepared by dissolving the appropriate quantity of pure liquid BBP in ethanol ( $98 \%$ of purity). Then different BBP concentrations(75-200 mg L-1)were prepared by dilution of stock BBPsolution (50 mg L"1). For each experiment, $50 \mathrm{~mL}$ of the solution were mixed with BBP concentration of $25 \mathrm{ppm}$ with $0.1 \mathrm{~g}$ of MWCNTs/ Ag composite in a $50 \mathrm{~mL}$ glass conical flask. The flask was shaken in a thermostatic orbit shaker at $220 \mathrm{rpm}$ for $12 \mathrm{~min}$. the mixed was filtered through a $0.45 \mu \mathrm{m}$ membrane filter. The filtrate was measured by Ultraviolet-visible spectroscopy(UV-Vis), and then the adsorption percentage $(\% \mathrm{~A})$ was determined as: 
$\% A=\frac{C_{0}-C_{e}}{C_{0}} \times 100$

Where $\mathrm{C}_{0}$ and $\mathrm{C}_{e}$ are the initial and final concentration of BBP in solution $(\mathrm{mg} / \mathrm{L})$, respectively. The amount $(\mathrm{mg} / \mathrm{g})$ of BBP adsorbed at equilibrium was calculated by using the following equation:

$q_{\theta}=\frac{\left(c_{0}-C_{\varepsilon}\right) \times V}{m}$

Where $m$ is the amount of adsorbent $(\mathrm{MWCNs} / \mathrm{Ag})(\mathrm{g})$ and $\mathrm{V}$ is the volume of the solution(L).

To evaluate the thermodynamic characteristics of the adsorption process, $0.1 \mathrm{~g}$ of MWCNTs/Ag composite was added into $100 \mathrm{~mL}$ initial

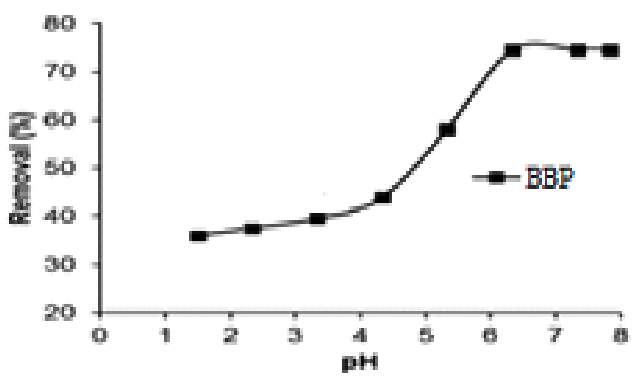

Fig. 3: Effect of solution $\mathrm{pH}$ on adsorption of BBPonto MWCNs/Ag (Conditions: sorbate concentration $50 \mathrm{mg} \mathrm{L}^{-1}$; Msorbent 0.1 $\mathrm{g}$; $\mathrm{t}=8 \mathrm{~min}$; $\mathrm{T}=298 \mathrm{~K}$ ).

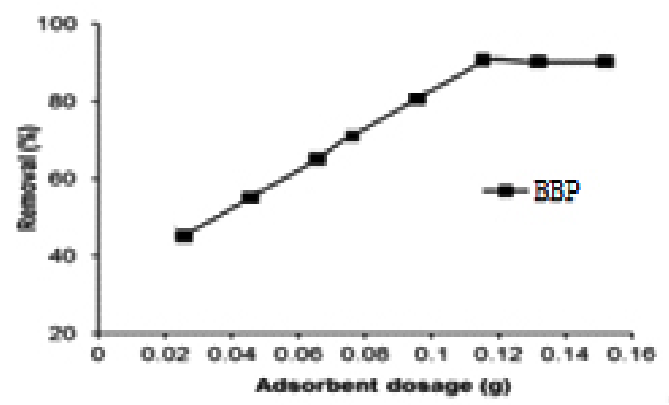

Fig. 5: Effect of adsorbent dosage on adsorption of BBPonto MWCNs/Ag

(Conditions: sorbate concentration $50 \mathrm{mg} \mathrm{L}^{-1}$; $\mathrm{pH}=6.5$; $\mathrm{t}=12 \mathrm{~min}$; $\mathrm{T}=298 \mathrm{~K}$ ).
BBP concentration ranging from 2 to $25 \mathrm{ppm}$ in each experiment. Each solution was shaken continuously for 6 and $12 \mathrm{~min}$ at $298 \mathrm{~K}$.

\section{Adsorption Isotherm}

Adsorption isotherms at 6 different BBP concentrations in the range of $75-200 \mathrm{mg} \mathrm{L}^{-1}$ were studied using the same above procedure. The solution $\mathrm{pH}$, contact time, sorbent amount, and temperature were adjusted in the optimum amounts obtained from batch optimization procedure, 6, 12 $\min , 0.12 \mathrm{~g}$ and $298 \mathrm{~K}$, respectively.

\section{Adsorption Kinetics}

Kinetics of Benzyl butyl phthalate(BBP) adsorption on the MWCNs/Ag were also investigated by the same above procedure using different contact times (2-12 $\mathrm{min}$ ) at optimum amounts of $\mathrm{pH}$, adsorbent dosage and temperature.

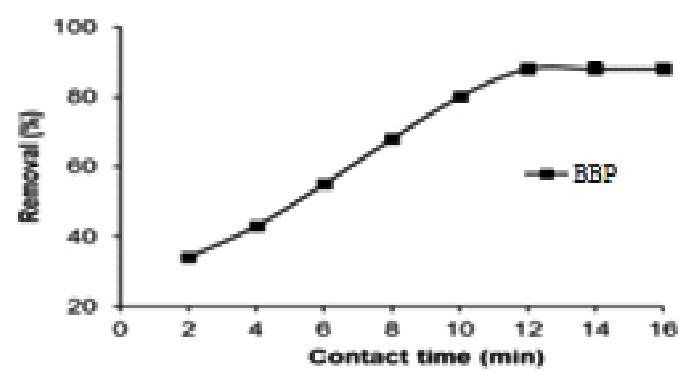

Fig. 4: Effect of contact time on adsorption of BBPonto MWCNs/Ag (Conditions: sorbate concentration $50 \mathrm{mg} \mathrm{L}^{-1} ; \mathrm{pH}=6.5$; Msorbent $0.1 \mathrm{~g}$; $\mathrm{T}=298 \mathrm{~K}$ ).

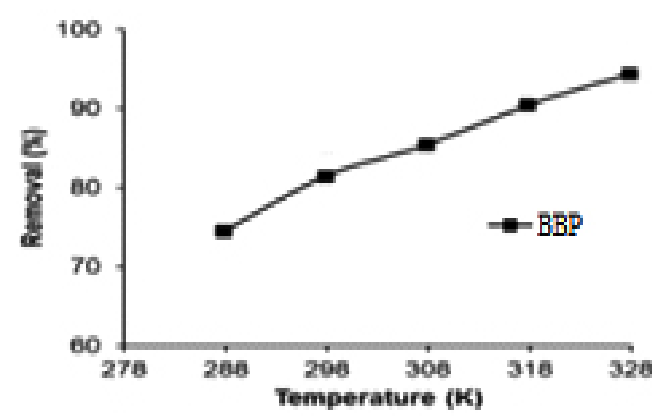

Fig. 6: Effect of temperature on adsorption of BBPonto MWCNs/Ag (Conditions:

sorbate concentration $50 \mathrm{mg} \mathrm{L}^{-1} ; \mathrm{pH}=6.5 ; \mathrm{t}=12$ min; Msorbent 008 g; T=298 K). 


\section{Adsorption Thermodynamics}

Thermodynamic studies at different temperatures $(288,298,308,318$, and $328 \mathrm{~K})$ were carried out by adding $0.1 \mathrm{~g}$ of MWCNs/Ag into 50 $\mathrm{mL}$ of BBPsolution (50 $\mathrm{mg} \mathrm{L}^{\mathrm{p}} 1$ ). The solution $\mathrm{pH}$ and ultrasonication time were adjusted in 6 and $12 \mathrm{~min}$, respectively.

\section{RESULTS and DISCUSSIONS}

\section{Characterization of Ag-MWCNTs}

The morphological features of the samples studied by SEM are shown in (Fig.1). Ag- MWCNTs are observed to be smooth, homogeneous, tidy and approximately uniform in size distribution (Fig.1). The IR spectrum of Ag -MWCNTs (Fig.2), shows absorption peak at $1715 \mathrm{~cm}^{-1}$ corresponding to the stretching vibration of carbonyl groups. The broad peaks at $1180 \mathrm{~cm}^{-1}$ could be assigned to $\mathrm{C}-\mathrm{O}$ stretching from phenolic, alcoholic, etheric groups and to $\mathrm{C}-\mathrm{C}$ bonds. The new peak appearing at 3400

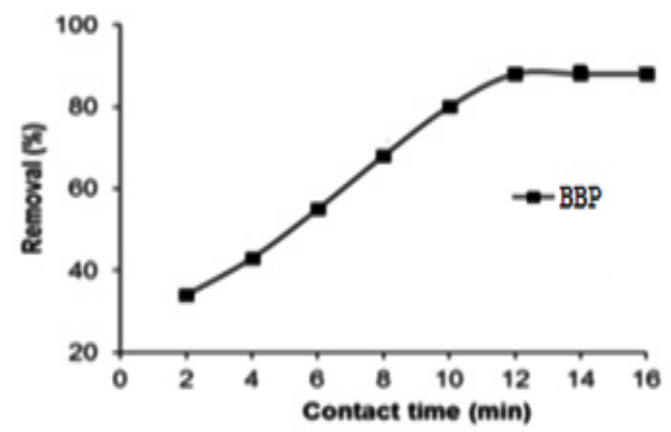

Fig. 7: Effect of contact time on adsorption of BBPonto MWCNs/Ag (Conditions: sorbate concentration $50 \mathrm{mg} \mathrm{L}-1$; $\mathrm{pH}=6.5$; Msorbent 0.1 g; T=298 K). $\mathrm{cm}^{-1}$ corresponds to $\mathrm{OH}$ stretching. This peak can be assigned to the hydroxyl group of moisture, or carboxylic groups. The aromatic $\mathrm{C}=\mathrm{C}$ stretch is observed at $\sim 1580 \mathrm{~cm}-1$ inspectra of MWCNT before the functionalization.

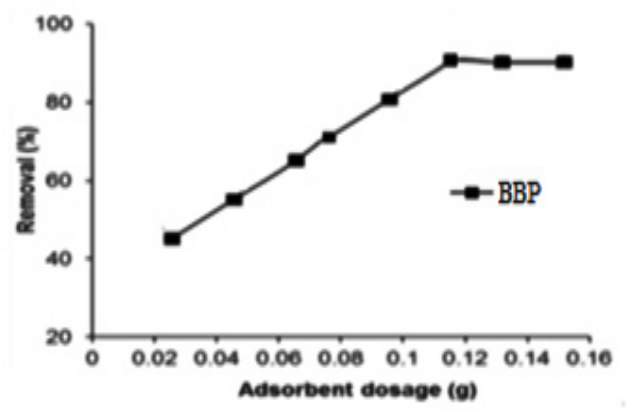

Fig. 8: Effect of adsorbent dosage on adsorption of BBPonto MWCNs/Ag (Conditions: sorbate concentration 50 mg L-1; $\mathrm{pH}=6.5$; $\mathrm{t}=12 \mathrm{~min}$; $\mathrm{T}=298 \mathrm{~K}$ ).

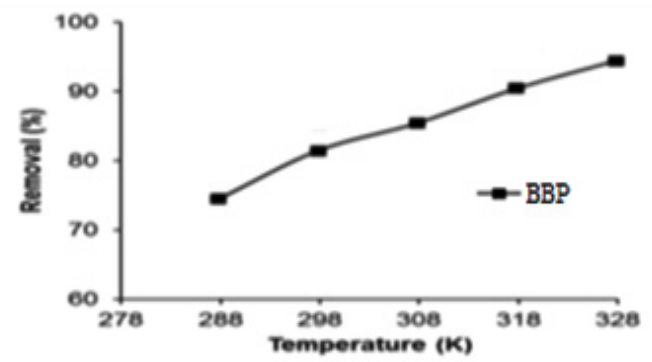

Fig. 9: Effect of temperature on adsorption of BBPonto MWCNs/Ag (Conditions: sorbate concentration $50 \mathrm{mg} \mathrm{L-1;} \mathrm{pH}=6.5$; $\mathrm{t}=12 \mathrm{~min}$; Msorbent $008 \mathrm{~g}$; T=298 K).

Table 1: Isotherm parameters for the adsorption of BBPonto MWCNs/Ag (Conditions:sorbate concentration 75-200 $\mathrm{mg} \mathrm{L}^{-1}$; Msorbent $0.12 \mathrm{~g}$; $\mathrm{t}=12 \mathrm{~min}$; $\mathrm{T}=298 \mathrm{~K}$ ).

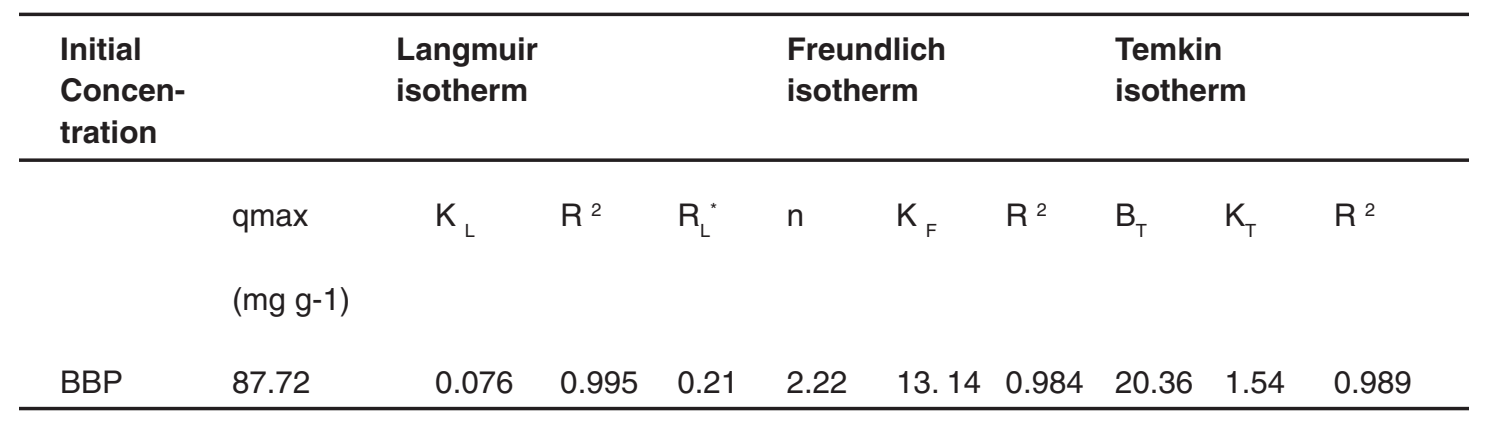




\section{Effect of pH}

The effect of $\mathrm{pH}$ on the adsorption of BBP by $0.1 \mathrm{~g}$ of $\mathrm{MWCNs} / \mathrm{Ag}$ was studied over the $\mathrm{pH}$ range of 1.5-8.0 (to avoid BBP precipitation), with known concentration of BBP $\left(50 \mathrm{mg} \mathrm{L}^{-1}\right)$, and ultrasonication time of $8 \mathrm{~min}$ at $25^{\circ} \mathrm{C}$. As illustrated in Figure 6, removal percentage of both $\mathrm{BBP}$ increased as the $\mathrm{pH}$ increased from 1.5 to 8.0 and then remajored constant up to $\mathrm{pH}=8.0$. At low $\mathrm{pH}$ values $(\mathrm{pH}<\mathrm{pHPZC}$ 6.5), solution is strongly acidic and the surface of the sorbent is surrounded by hydrogen BBP and due to the competition of protons with Benzyl butyl phthalate(BBP), the removal percentages were low. At higher $\mathrm{pH}$ values ( $\mathrm{pH}>\mathrm{pHPZC} \mathrm{6.5)}$, the sorbent surface becomes negatively charged (MWCNs/Ag) due to the deprotonation reaction, so, the increased removal of $\mathrm{BBP}$ is due to the strong electrostatic attraction between the sorbent surface and BBP. Accordingly, $\mathrm{pH}=6.5$ was chosen as the optimal $\mathrm{pH}$ for all further studies.

\section{Effect of Contact Time}

The effect of contact time on the removal Benzyl butyl phthalate (BBP) by MWCNs/Ag was studied using different ultrasonication times from 2 to $16 \mathrm{~min}$ with $50 \mathrm{~mL}$ of $50 \mathrm{mg} \mathrm{L}^{-1}$ Benzyl butyl phthalate(BBP)solution $(\mathrm{pH}=6.5)$, and $0.1 \mathrm{~g}$ of MWCNs/Ag at temperature of $298 \mathrm{~K}$. As can be seen from Figure 7 that the adsorption rate of BBP onto the adsorbent was very rapid initially, which indicates that there were enough adsorption sites for the BBP to be accommodated. Subsequently, the adsorption rate slowly decreased as the adsorption sites became gradually saturated, and finally it reached equilibrium in $12 \mathrm{~min}$ and remajored constant up to $16 \mathrm{~min}$. Therefore, $12 \mathrm{~min}$ was selected as optimum contact time for subsequent isotherm studies.

\section{Effect of Adsorbent dosage}

Adsorption of Benzyl butyl phthalate(BBP) was studied using different dosages of MWCNs/Ag (0.02-0.16 g) at the optimum $\mathrm{pH}$ and contact time. As shown in Figure 8, increase in adsorbent dosage enhanced clearly the percent removal of Benzyl butyl phthalate(BBP)from aqueous solution. The maximum removal of both Benzyl butyl phthalate(BBP)was obtained for the adsorbent dosage of $0.12 \mathrm{~g}$. At low adsorbent dosages, the absorbent surface became saturated with the BBP and the residual BBP concentration in the solution was large. As the adsorbent dosage increases, the adsorbent sites available for Benzyl butyl phthalate(BBP)are also increased and consequently further adsorption takes place. However, higher dosages $(>0.12 \mathrm{~g}$ ) had no significant effect on the BBP uptake as the BBP concentration and the solution BBP concentration came to equilibrium with each other. Accordingly, 0.12 of $\mathrm{MWCNs} / \mathrm{Ag}$ was used in all subsequent experiments

\section{Effect of Temperature}

The adsorption experiments of Benzyl butyl phthalate(BBP) were performed at five different temperatures in the range of $288-328 \mathrm{~K}$ with $50 \mathrm{~mL}$ of $50 \mathrm{mg} \mathrm{L}^{-1}$ aqueous Benzyl butyl phthalate(BBP) solution and $0.08 \mathrm{~g}$ of MWCNs/Ag at $\mathrm{pH}$ of 6.5 , and contact time of $12 \mathrm{~min}$. From Figure 9, the removal percentage of both Benzyl butyl phthalate(BBP) by $\mathrm{MWCNs} / \mathrm{Ag}$ increases with the rise in solution temperature from $288 \mathrm{~K}$ to $308 \mathrm{~K}$, suggesting that the adsorption process is endothermic. This increase can be due to the increased mobility of Benzyl butyl phthalate(BBP)and to their tendency to adsorb from the solution to the surface of the adsorbent as well as due to a greater activity of binding sites as the temperature increases.

\section{Adsorption Isotherms}

In the present work, the sorption data have been subjected to different sorption isotherms, namely, Langmuir, Freundlich and Temkin models. Langmuir adsorption isotherm is valid in the case of monolayer adsorption onto the surface with a finite number of identical sites ${ }^{28}$. Freundlich isotherm is used for the description of multilayer adsorption with interaction between adsorbed molecules ${ }^{29}$. The Temkin isotherm model assumes that the adsorption energy decreases linearly with the surface coverage due to some indirect adsorbate/ adsorbateinteractions ${ }^{30}$. The linear forms of isotherm models are defined as:

$$
\begin{aligned}
& \mathrm{Ce} / \mathrm{qe}=1 / \mathrm{K}_{\mathrm{L}} \mathrm{q}_{\max }+\mathrm{Ce} / \mathrm{q}_{\max } \\
& \mathrm{q}_{\mathrm{e}}=\mathrm{k}_{\mathrm{f}} \mathrm{C}_{\mathrm{e}} 1 / \mathrm{n} \rightarrow \ln \mathrm{q}_{\mathrm{e}}=\ln \mathrm{k}_{\mathrm{f}}+1 / \mathrm{n} \ln \mathrm{C}_{\mathrm{e}} \\
& \mathrm{qe}=\mathrm{BT} \ln \mathrm{KT}+\mathrm{BT} \ln \mathrm{Ce}
\end{aligned}
$$

The experimental equilibrium adsorption data were fitted above equations using plot of 
$C_{e} / q_{e}$ versus $C_{e}$, $\operatorname{lnq} q_{e}$ versus $\ln C_{e}$, and $q_{e}$ versus $\ln C_{e}$, respectively. Isotherm constants were determined from the slopes and intercepts of the corresponding linear plots. In Langmuir model, qe is the amount of heavy metal ion adsorbed at equilibrium $\left(\mathrm{mgg}^{-1}\right)$, qmax is maximum adsorption valency $\left(\mathrm{mgg}^{-1}\right)$ on unit mass of adsorbent, and $\mathrm{K}_{\mathrm{L}}$ is the Langmuir constant $\left(\mathrm{Lmg}^{-1}\right)$, related to the free energy of adsorption. Furthermore, the essential characteristic of the Langmuir isotherm, dimensionless separation factor $\left(R_{L}\right)$ was calculated using Eq.(6). The $R L$ values between 0 and 1 indicate favorable adsorption. In Freundlich isotherm KF and $\mathrm{n}$ are the isotherm constants related to adsorption valency ( $\left.\mathrm{mg}^{11} 1 / \mathrm{nL}^{1} / \mathrm{ng}^{11}\right)$ and adsorption intensity, respectively. In Temkin model, $\mathrm{K}_{\mathrm{T}}$ is the equilibrium binding constant $\left(\mathrm{L} \mathrm{mg}^{-1}\right)$ and $\mathrm{BT}$ is a constant related to adsorption heat $\left(\mathrm{kJ} \mathrm{mol}^{-1}\right)$.

$$
R_{L}=1 / 1+K_{L} C_{0}
$$

The results obtained by fitting the experimental equilibrium adsorption data to the isotherm models as well as the correlation coefficients $\left(R_{2}\right)$ for all the models were presented in Table 1. Examination of the linear isotherm plots suggested that, for the adsorption of Benzyl butyl phthalate (BBP) onto MWCNs/Ag adsorbent, the
Langmuir isotherm yielded a much further fit with higher correlation coefficient $(R 2>0.99)$ than the other models. Also, the values of $\mathrm{RL}$ are in the range of $0-1$, which confirms the favorable uptake of BBP by the MWCNs/Ag adsorbent. Therefore, uptake of both BBP by MWCNs/Ag preferably followed the mono layer adsorption process.

\section{Adsorption Kinetics}

In order to investigate the mechanism of Benzyl butyl phthalate(BBP) adsorption on the adsorbents and examine the potential ratecontrolling step, mass transfer or chemical reaction, different kinetic models were studied. The capability of Lagergren's pseudo-first-order, pseudo-secondorder, and intraparticle diffusion models was examined in this study. The correlation coefficient $\left(R_{2}\right.$, close or equal to 1) was introduced to evaluate the suitability of different models. The linearized-integral forms of studied kinetic models are expressed $\mathrm{as}^{31-35:}$

$$
\begin{gathered}
\ln \left(q_{1}-q_{t}\right)=\ln q_{1}-k 2 t \\
t / q_{t}=1 / k_{2} q^{2}+t / q_{2} \\
q_{t} k_{i} t^{2 / 1}+C_{i}
\end{gathered}
$$

Table 2: Kinetic parameters for the adsorption of BBPonto MWCNs/Ag (Conditions: sorbate concentration $50 \mathrm{mg} \mathrm{L}^{-1}$; Msorbent $0.12 \mathrm{~g}$; t=2-10 $\mathrm{min}$; T=298 K).

\begin{tabular}{|c|c|c|c|c|c|c|}
\hline \multirow[t]{2}{*}{ Metal ion } & \multirow[t]{2}{*}{ Parameter } & \multicolumn{5}{|c|}{ Temperature (K) } \\
\hline & & 288 & 298 & 308 & 318 & 328 \\
\hline & $\Delta / \mathrm{H}^{0}\left(\mathrm{~kJ} \mathrm{~mol}^{-1}\right)$ & & 22.94 & & & \\
\hline \multirow[t]{2}{*}{ BBP } & $\Delta / \mathrm{G}^{0}\left(\mathrm{~kJ} \mathrm{~mol}^{-1}\right)$ & -0.04 & -0.87 & -1.47 & -2.36 & -3.29 \\
\hline & $\Delta / \mathrm{S}^{0}\left(\mathrm{~kJ} \mathrm{~mol}^{-1} \mathrm{~K}^{-1}\right)$ & & 0.08 & & & \\
\hline
\end{tabular}

\begin{tabular}{llccccccccc}
\hline $\begin{array}{l}\text { Metal Ion } \\
\text { order kinetic }\end{array}$ & $\begin{array}{l}\text { Pseudo first - } \\
\text { order }\end{array}$ & & \multicolumn{3}{c}{$\begin{array}{c}\text { Pseudo second- } \\
\text { order kinetic }\end{array}$} & \multicolumn{3}{c}{$\begin{array}{c}\text { Intra particle } \\
\text { diffusion }\end{array}$} \\
\hline & $\mathrm{q} 1(\mathrm{mg} \mathrm{g-1)}$ & $\mathrm{K}_{1}$ & $\mathrm{R}^{2}$ & $\mathrm{q} 2(\mathrm{mg} \mathrm{g-1})$ & $\mathrm{K}_{2}$ & $\mathrm{R}^{2}$ & $\mathrm{~K}_{\mathrm{i}}$ & $\mathrm{C}_{\mathrm{i}}$ & $\mathrm{R}^{2}$ \\
$\mathrm{BBP}$ & 0.236 & 22.64 & 0.981 & 30.76 & 0.005 & 0.996 & 6.519 & 1.557 & 0.988 \\
\hline
\end{tabular}

Table 3.Thermodynamic parameters for the adsorption of BBPonto MWCNs/Ag (Conditions: sorbate concentration $50 \mathrm{mg} \mathrm{L-1}$; Msorbent $0.08 \mathrm{~g}$; t=12min). 
Where $\mathrm{q}^{1}$ (or $\left.\mathrm{q}^{2}\right)$ and $\mathrm{qt}\left(\mathrm{mg} \mathrm{g}^{-1}\right)$ are the values of amount adsorbed per unit mass of sorbent at equilibrium and at any time t. $\mathrm{k}^{1}\left(\mathrm{~min}^{-1}\right)$ is the pseudo-first-order adsorption rate coefficient and $\mathrm{k}_{2}$ $\left(\mathrm{g} \mathrm{mg}^{-1} \mathrm{~min}^{-1}\right.$ ) is the pseudo-second-order constant.

The values of $k_{2}$ were calculated from the slopes of the respective linear plots of $t / q_{t} v s$. $t$. In intraparticle diffusion model $\mathrm{k}_{\mathrm{i}}\left(\mathrm{mg} \mathrm{g}^{-1} \mathrm{~min}^{-1 / 2}\right)$ is the diffusion rate coefficient and $\mathrm{C}_{i}$ is the intercept and relate to the thickness of the boundary layer. The parameter values for each model were obtained from the respective fitting curve resulting from the linear form of pseudo-first order, pseudo-second order and intra-particle The results along with the correlation coefficients $\left(R_{2}\right)$ were listed in Table 2 .

Comparing the correlation coefficients of kinetic models revealed that the pseudo-secondorder kinetic model with $R_{2}$ values close to 1 matched further the experimental data than the other models.

This model is based on the assumption that the rate limiting step may be a chemical sorption involving valence forces through sharing or exchange of electrons between the adsorbent and the adsorbate ${ }^{36}$.

\section{Adsorption Thermodynamics}

Thermodynamic studies are used to decipher any reaction in a further way. In the present study, the variation in the extent of adsorption with respect to temperature has been explained based on thermodynamic parameters viz. changes in standard free energy $\left(\Delta \mathrm{G}^{0}\right)$, enthalpy $\left(\Delta \mathrm{H}^{0}\right)$ and entropy $\left(\Delta \mathrm{S}^{0}\right)$. Thermodynamic parameters were evaluated in the temperatures range of $288-328 \mathrm{~K}$ (to avoid thermal decomposition of adsorbent). The values of the thermodynamic parameters were calculated using the thermodynamic equations described below ${ }^{37,38}$ :

$$
\begin{aligned}
& \Delta G^{\circ}=-R T \ln K_{C} \\
& \quad \operatorname{Ln} K_{C}=\Delta S^{\circ} / R-\Delta H^{\circ} / R T
\end{aligned}
$$

Pseudo second-order kinetic Where $\mathrm{R}$ the ideal gas constant $\left(8.314 \mathrm{~J} \mathrm{~mol}^{-1} \mathrm{~K}^{-1}\right), \mathrm{T}$ is the absolute temperature $(\mathrm{K})$, and $\mathrm{K}_{\mathrm{c}}$ is the thermodynamic equilibrium constant defined by $\mathrm{q}_{\mathrm{e}} / \mathrm{C}_{\mathrm{e}} \cdot \Delta \mathrm{H}^{0}$ and $\Delta \mathrm{S}^{0}$ values were obtained from slope and intercept of the plot InK $\mathrm{K}_{\mathrm{c}}$ versus $1 / \mathrm{T}$. The values of thermodynamic parameters thus calculated were recorded in Table 3.

Positive $\Delta \mathrm{H}^{0}$ values at different temperatures suggested the endothermic nature of adsorption process, which was in good agreement with the results that the adsorption of Benzyl butyl phthalate(BBP) increased with the increasing temperature. Positive $\Delta \mathrm{S}^{0}$ values showed an increased randomness during Benzyl butyl phthalate(BBP)adsorption. Negative $\Delta \mathrm{G}^{0}$ values indicated that the adsorption reaction of both metal ions was spontaneous.

\section{CONCLUSION}

In this research, It was observed that the Mullti-walled Carbon Nanotubes modified with $\mathrm{Ag}(\mathrm{MWCNs} / \mathrm{Ag})$ is an efficient adsorbent for the removal of Benzyl butyl phthalate(BBP). The maximum elimination percentage of the studied Benzyl butyl phthalate(BBP) $(\mathrm{R}=99 \%)$ was obtained at optimum conditions: $\mathrm{pH}$ of $6.5,0.12 \mathrm{~g}$ of sorbent, 12 min ultrasonication time, and $298 \mathrm{~K}$. The isotherm models such as Langmuir, Freundlich, and Tempkin were measured and the equilibrium data were best described by the Langmuir model. The adsorption process was fast and pseudo-secondorder rate model accurately described the kinetics of adsorption, which suggested chemisorption as the rate-constraining step in the adsorption process. Based on thermodynamic studies, the adsorption process of metal ions was both endothermic and spontaneous. Ased on the results, the proposed sorbent is useful for quantitative adsorption of BBPwith high sorption valencies in short time.

\section{ACKNOWLEDGMENTS}

The author gratefully acknowledge the financial support for this project from the Science and Research Branch Islamic Azad University, Tehran, Iran. 


\section{REFERENCES}

1. Sharpe, R.M., Hormones and testis development and the possible adverse effects of environmental chemicals. Toxicol. Lett.2010, 120, 221-232.

2. Cao, X.L., Compr. Rev. Food Sci. Food Saf.2010, 95, 21-29.

3. Rios, J.J., Morales, A., Marquez-Ruiz, G. Talanta. 2010, 80, 2076.

4. Wang, F., Yao, J., Sun, K., Xing, B.S. Environ. Sci. Technol. 2010, 44, 6985.

5. Camenzind, M.J.,Chargin, C.J., Kumar, A. Santa Clara, CA, 1999, 51-68.

6. Jobling, S., Reynolds, T., White, R., Parker, M.G., Sumper, J.P.Environ. Health Persp.1995, 103, 582-587.

7. Harris, C.A., Henttu, P., Parker, M.G., Sumpter, J.P.The estrogenic activity of phthalate esters in vitro, Environ.Health Persp.1997, 105, 802-810.

8. Zacharewski, T., Bondy, K.L., McDonnell, P., Wu, Z.F. Environ. Health Persp.1998, 106, 577-582.

9. Chatterjee, S., Dutta, T.K. Metabolism of butyl benzyl phthalate by Gordoniasp. strain MTCC Biochem. Biophys. Res. Commun. 2003, 309, 36-43.

10. (a) Xu, X.R., Li, H.B., Gu, J.D., Li, X.Y. J. Hazard. Mater.2007, 140, 194-199. (b) Rege, S.U., Yang, R.T. Corrected horvathkawazoeequations for pore-size distribution.AIChE J. 2000, 46(4), 734-750.

11. Qiao, F., Wang, M. J. Chromatogr. B 2016, 18-27.

12. Hao, R., Xing, R. J., Xu, Z. C., Hou, Y. L., Gao, S., Sun, S. H. Adv. Mater. 2010, 25, 27292742.

13. Chen, T., Yang, W., Guo, Y., Yuan, R., Xu, L., Yan, Y. Enzyme Microb. Technol. 2014, 5057.

14. Abedi, S., ZavvarMousavi, H., Asghari, Desalin. A. Water Treat. 2015, 1-9.

15. Roosta, M., Ghaedi, M., Daneshfar, A., Sahraei, R., Asghari, A. Ultrason. Sonochem.2014, 21, 242-249.

16. Khaligha, A., ZavvarMousavi, H., Rashidi, A. Journal of Applied Chemistry, 2017, 11, 49-59.
17. Wang, X.S., Li, Q.Q., Xie, J., Jin, Z., Fan, S.S. Nano Lett. 2009, 9, 3137-3143.

18. Dillon, A.C., Heben, M.J. Appl. Phys. 2001, 72, 131-139.

19. Hoc, Y.S., Huang, T., Huang, H. W. Process Biochem. 2002, 37, 1421-1428.

20. Wildgoose, G.G., Banks, G.E., Compton, R.G. Small. 2006, 2, 182-193.

21. Georgakilas, V., Gournis, D., Tzitzios, V., Pasquato, L., Guldi, D.M., Prato, M. J Mater Chem. 2007, 17, 2679-2694.

22. Kim, B., Sigmund, W.M. Functionalized multiwall carbon nanotube/gold nanoparticle composites. Langmuir. 2004, 20(19), 82398242.

23. Zanella, R., Basiuk, E.V., Santiago, P., Basiuk, V.A., Mireles, E. J PhysChem B 2005, 109(34), 16290-16295.

24. Guo, D.J., Li, H.L. Carbon. 2005, 43(6), 1259-1264.

25. Chin, K.C., Gohel, A., Chen, W.Z., Elim, H.I., Ji, W., Chong, G.L. ChemPhysLett. 2005, 409(1-3), 85-88.

26. Wu, H.P., Wu, X.J., Ge, M.Y., Zhang, G.Q., Wang, Y.W., Jiang, J. Compos SciTechol, 2007, 67(6), 1182-1186.

27. Lee, S.M., Tiwari, D. Chem. Eng. J. 2013, 225, 128-135.

28. Langmuir, I., J. Am. Chem. Soc. 1918, 40, 1361-1369.

29. Hughes, M.F., Beck, B.D., Chen, Y., Lewis, A.S., Thomas, D.J. Toxicol. Sci. 2011, 123, 305-312.

30. Temkin, M., Pyzhev, V. ActaPhysiochim. USSR. 1940, 12, 217-226.

31. (a) Javad, S., Aghaie, H., Ghaedi, M. Oriental Journal of Chemistry, Methodology. 2014, 30(4), 1883-1895. (b) Mohammadkhani, S., Gholami, M.R., M. Aghaie. Orient. J. Chem. 2016, 32(1), 591-599.

32. Ho, Y.S., McKay, G. Process Biochem. 1999, 34, 451-461.

33. Ghaedi, M., Sadeghian, B., Pebdani, A.A., Sahraei, R., Daneshfar, A., Duran, C. Chem. Eng. J. 2012, 187, 133-141.

34. Hajati, S., Ghaedi, M., Barazesh, B., Karimi, F., Sahraei, R., Daneshfar, A., Asghari, A. J. 
Ind. Eng. Chem. 2014, 20, 2421-2427.

35. Toor, M., Jin, B. Chem. Eng. J. 2012, 187, 79-88.

36. Panadare, D.C., Lade, V.G., Rathod, Desalin. V.K. Water Treat. 2013, 1-9.
37. Rahmani, A., Mousavi, H.Z., Fazli, M. Desalination, 2010, 253, 94-102.

38. Pehlivan, E., Arslan, G. Fuel Process. Technol. 2007, 88, 99-108. 